\title{
Implications of Fraud and Abuse in Interventional Pain Management
}

\author{
Laxmaiah Manchikanti, MD
}

The federal government has enacted a comprehensive strategy to fight healthcare waste, fraud and abuse. As a result of the federal government's comprehensive strategy, in 2002, the Office of Inspector General announced that improper Medicare payments to doctors, hospitals and other healthcare providers declined 54\% from the fiscal year 1996 to the fiscal year 2001. The Office of Inspector General in its 2002 work plan focuses on procedure coding for outpatient services billed by hospital and doctor, coding for evaluation and management services in physician offices and conditions under which a doctor's bill is "incident to" services or supplies among other things.

The distinction between fraud and abuse can be very important in determining the potential fines and penalties that might apply, even though it is not clear. Fraud is much more serious than abuse. The degree of intent by the individual or entity under investigation is often the determining factor.
The most commonly used statutes for prosecuting or facilitating such a prosecution of healthcare fraud or abuse include HIPAA of 1996, the False Claims Act, healthcare fraud, theft or embezzlement, obstruction of criminal investigations of healthcare offenders, the False Statement Statute, mail and wire fraud statutes, the Social Security Act Civil Monetary Penalties, criminal penalties, and/or Stark laws.

This review focuses on various aspects of implications of fraud and abuse in interventional pain management practices including various activities of potential fraud and abuse.

Keywords: Fraud, Abuse, Centers for Medicare and Medicaid Services, Health Insurance Portability and Accountability Act, Office of Inspector General
Fraud and abuse is an important issue for the Department of Health and Human Services (DHHS). This is one area where the agency recovers much more than it puts in. This is also an area of multiple agencies being involved in working against one common enemy, ie, the provider of health care services. Multiple federal agencies involved in fraud and abuse investigations and enforcement of charges are not only limited various departments within the DHHS (Centers for Medicare and Medicaid, HHS Office of Audit Services, carriers, intermediaries, HHS Office of Investigations), but also includes the Office of Inspector General (OIG), the Department of Justice (DOJ), the Federal Bureau of Investigations, the Drug Enforcement Agency, the Internal Revenue Service (IRS), the US Postal Service, the US Attorney General, local Medicare fraud units and Public Relation's Office (PRO), etc. Multiple non-federal agencies include State Cabinets for Health and Human Services, licensure agencies, State

From Pain Management Center of Paducah, Paducah, Kentucky. Dr Manchikanti is the medical director of Pain Management Center of Paducah. Address correspondence: Laxmaiah Manchikanti, 2831 Lone Oak Road, Paducah, KY 42003. E-mail: drm@asipp.org
Attorney General, Medicaid fraud units and State Bureau of Investigations, etc. Further, any third party payor, selfinsured insurer, beneficiary or relative, competitors, present and previous employees.

The federal government has enacted over the years a comprehensive strategy to fight healthcare waste, fraud and abuse. The Clinton Administration focused unprecedented attention on the fight against fraud, abuse and waste in the Medicare and Medicaid programs beginning in 1993. As a result of this focus, in 2002, the OIG announced that improper Medicare payments to doctors, hospitals, and other healthcare providers declined 54\% from fiscal year 1996 to fiscal year 2001. Federal authorities also have claimed that, due to this investigation, a new, more detailed picture of fraudulent activities at the Medicare and Medicaid systems has emerged. Former HHS Secretary, Donna Shalala, launched Operation Restore Trust, a groundbreaking project aimed at coordinating federal, state, local and private resources and targeting them on areas most plagued by abuse. During its 2-year demonstration phase, the project apparently identified \$23 in overpayments for every dollar of project cost. In addition, the former Secretary also led the way to steady, guaranteed funding for anti-fraud efforts by the 
Table 1. OIG and DOJ focus on some of the aspects of Medicare fraud and abuse

\begin{tabular}{|c|c|c|}
\hline Focus of OIG for 2002 & Cases of Interest to FBI & $\begin{array}{c}\text { "Overnight Files" from a week } \\
\text { in } 2002 \text { from a US attorney's } \\
\text { office }\end{array}$ \\
\hline $\begin{array}{l}\text { Procedure coding for outpatient } \\
\text { services billed by a hospital and doctor }\end{array}$ & - Identity theft & Billing for unnecessary services \\
\hline $\begin{array}{l}\text { Use of Medicare advance benefi- } \\
\text { ciary notices and their financial impact- } \\
\text { on physicians and beneficiaries }\end{array}$ & - Unnecessary services & $\begin{array}{l}\text { Inflation of number of visits by } \\
\text { home health agencies }\end{array}$ \\
\hline $\begin{array}{l}\text { Coding for evaluation and manage- } \\
\text { ment services in physicians offices }\end{array}$ & - Gifts from suppliers & $\begin{array}{l}\text { Billing used equipment as if it } \\
\text { were new by Durable Medical } \\
\text { Equipment (DME) companies }\end{array}$ \\
\hline \multirow[t]{2}{*}{$\begin{array}{l}\text { Conditions under which a doctor's } \\
\text { bill is "incident to" services or supplies }\end{array}$} & $\begin{array}{l}\text { Diversion of prescription } \\
\text { drugs }\end{array}$ & $\begin{array}{l}\text { Billing basic service as if it were } \\
\text { advanced life support by } \\
\text { transportation companies }\end{array}$ \\
\hline & $\begin{array}{l}\text { Clinical research subject } \\
\text { recruitment }\end{array}$ & $\begin{array}{l}\text { Billing for group therapy by } \\
\text { mental health facilities }\end{array}$ \\
\hline
\end{tabular}

HHS Inspector General, by including these provisions in the HIPAA of 1996.

Under HIPAA's Healthcare Fraud and Abuse Control Program, HHS has reported more than $\$ 1.9$ billion in fines and restitution returned to the Medicare trust fund during fiscal years 1997, 1998 and 1999. The HHS also excluded more than 23,186 individuals and entities from doing business with Medicare, Medicaid and other federal and state healthcare programs for engaging in fraud or other professional misconduct. There was a substantial increase from 1996 to 2001 compared to previous years. The HHS has stated that, since 1993, these actions have saved HHS healthcare programs more than $\$ 38$ billion and have increased convictions and other successful legal actions by more than $240 \%$.

\section{STRATEGIC FOCUS ON FRAUD AND ABUSE}

The federal government is focusing on fraud and abuse with continued interest and enthusiasm in healthcare. Table 1 illustrates the OIG's focus for 2002, interesting items for the FBI and the description of some of the examples of US Attorney's office in Philadelphia's so called "overnight files" from the last week of January in 2002.

In a statement before House Budget Committee, OIG re- ported the following):

".... we would like to express our belief that the vast majority of health care providers are honest in their dealings with Medicare. When we talk about fraud, we are not talking about providers who make innocent billing errors, but rather those who intentionally set out to defraud the Medicare program or abuse Medicare beneficiaries. The importance of our ongoing work is not only to protect the taxpayers and ensure quality healthcare for Medicare beneficiaries but also to make the Medicare environment one in which honest providers can operate on a level playing field and do not find themselves in unfair competition with criminals.

At the same time, we are concerned about all errors, even those that are totally innocent. The complexity of the Medicare program places an obligation on health care providers, beneficiaries, fiscal intermediaries, carriers, and the Health Care Financing Administration (HCFA) to take reasonable care to comply with its rules. Thus, our audits and studies are also intended to identify vulnerabilities to administrative errors and to the related dollar losses, which can be quite significant." 


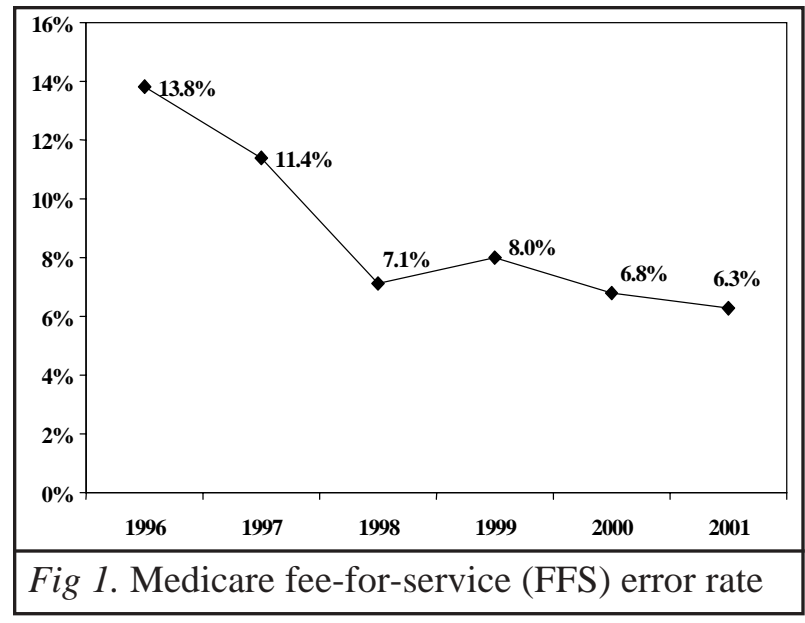

The OIG also reported the following:

"The HCFA is the single largest purchaser of health care in the world. With expenditures of approximately $\$ 316$ billion, assets of $\$ 212$ billion, and liabilities of $\$ 39$ billion, HCFA is also the largest component of the Department. In 1999, Medicare and Medicaid outlays represented 33.7 cents of every dollar of health care spent in the United States. In view of Medicare's 39.5 million beneficiaries, 870 million claims processed and paid annually, complex reimbursement rules, and decentralized operations, the program is inherently at high risk for payment errors and fraudulent schemes.
Like other insurers, Medicare makes payments based on a standard claim form. Providers typically bill Medicare using standard procedure codes without submitting detailed supporting medical records. However, regulations specifically require providers to retain supporting documentation and to make it available upon request. The OIG is statutorily charged with protecting the integrity of our Department's programs, as well as promoting their economy, efficiency, and effectiveness. The OIG meets this mandate through a comprehensive program of audits, program evaluations, and investigations designed to improve the management of the Depart; to detect and prevent waste, fraud and abuse; and to ensure that beneficiaries receive high-quality, necessary services at appropriate payment levels. As part of this effort, we conduct annual audits of the Department's and HCFA's financial statements, as required by the Chief Financial Officers Act, as amended by the Government Management Reform Act of 1994."

\section{FEDERAL COMPREHENSIVE STRATEGY}

As a result of this focus, in 2002, the OIG announced that improper Medicare payments to doctors, hospitals, and other healthcare providers declined 54\% from fiscal year 1996 to fiscal year 2001 (Fig. 1). Federal authorities also have claimed that, due to this investigation, a new, more

Table 2. Clinton Administration's focus on fraud and abuse

1. To reduce improper payments by $50 \%$

2. Operation Restore Trust

3. A fraud and abuse hotline

4. The administration on Aging Ombudsman Program

5. Expanded OIG and funding

6. Increased efforts by the DOJ

7. Rewards for fraud and abuse information

8. Tightening of standards for home healthcare providers

9. New requirements for durable medical equipment suppliers

10. Targeting of fraud in community mental health centers

11. The Medical Integrity Program and payment safeguards

12. Improving healthcare industry compliance

13. Correct coding initiatives

14. Substantive claims testing

15. Education efforts

16. Tough new requirements for Medicare and Medicaid participants

17. Budget 2000 anti-fraud and abuse legislative package 
detailed picture of fraudulent activities at the Medicare and Medicaid systems has emerged. It was also claimed that new service and audits have helped investigators pinpoint areas of vulnerability and ongoing patterns of abuse, which in turn are leading to changes in law enforcement and administrative actions. Further, the government has gone so far that it is recruiting beneficiaries themselves to spot and report fraud and misspending.

Under HIPAA's Healthcare Fraud and Abuse Control Program, HHS has reported more than $\$ 1.9$ billion in fines and restitution returned to the Medicare trust fund during fiscal years 1997, 1998 and 1999. The HHS also excluded more than 23,186 individuals and entities from doing business with Medicare, Medicaid and other federal and state healthcare programs for engaging in fraud or other professional misconduct (Table 2). There was a substantial increase from 1996 to 2001 compared to previous years. The HHS has stated that, since 1993, these actions have saved HHS healthcare programs more than $\$ 38$ billion and have increased convictions and other successful legal actions by more than $240 \%$. Table 3 illustrates increased spending for fraud and abuse control.

Various efforts of the Clinton Administration in fighting waste, fraud and abuse in Medicare and Medicaid are listed in Table 4.

\section{Fraud and Abuse Targets}

For the past 3 years, physician practices have been aggressively audited by the federal and state governments, along with major third-party payors across the nation. Since 1993, when President Clinton's administration began to delve into healthcare fraud and abuse, there have been a record number of investigations, indictments, convictions and settlements in almost every segment of the healthcare community. Thus, when the federal government stated that in 1999 alone, it recovered nearly $\$ 500,000,000$ as a result of auditing providers for fraud, abuse and/or healthcare waste and when it said that federal officials have recovered an estimated \$1.9 billion since 1996, with another $\$ 60,000,000$ saved in improper and wasteful spending prevention, it was not an overstatement. Provider exclusions as of March 2000 since the inception of the program were $\$ 16,167$ compared to $\$ 21,644$ by May of 2001 and $\$ 23,186$ by October 2001. Table 3 shows Medicare exclusions and sanctions.

Similarly, the government also has recovered significant amounts and returned the funds to the Medicare trust fund compared to the funds appropriated from the federal budget on fraud and abuse, as shown in Fig. 2. It also has been illustrated that government's health related civil fraud recoveries have been gradually increasing not only in the amount, but also in proportion compared to total civil fraud recoveries (Fig. 3).

\section{The OIG 2002 Work Plan}

The OIG's 2002 work plan encompasses significantly increased levels of activity compared to 2001 . The number of initiatives in 2001, 19 has been increased to 25 in 2002. Further, 13 of those 25 initiatives are new. Three of the new projects on the OIG's list have to do with the outpatient prospective payment system. Of these, nine projects

Table 3. Fraud and abuse budget of US government

\begin{tabular}{lccc}
\hline & US Government Fraud and Abuse Budget & & \\
\cline { 2 - 4 } & $\begin{array}{r}\mathbf{2 0 0 0} \text { actual } \\
\text { (in \$ millions) }\end{array}$ & $\begin{array}{c}\mathbf{2 0 0 1} \text { enacted } \\
\text { (in \$ millions) }\end{array}$ & $\begin{array}{c}\text { 2002 request } \\
\text { (in \$ millions) }\end{array}$ \\
\hline Total CMS & 316,007 & 354,485 & 386,527 \\
Total Medicare & 196,866 & 219,119 & 229,744 \\
Total OIG & 151 & 164 & 186 \\
Health care fraud and abuse control (HCFAC) & 715 & 820 & 860 \\
CMS's Medicare integrity program & 630 & 680 & 700 \\
FBI refunds for health care fraud investigations & 76 & 88 & 101 \\
Other fraud and abuse control & 158 & 182 & 209 \\
\hline Source: FY 2002 HHS Budget & & &
\end{tabular}


Table 4. Medicare exclusions and sanctions as of December 2001

\begin{tabular}{lc}
\hline Provider Type & Total Exclusions \\
\hline Private citizen & 4,075 \\
Hospital (employee) & 1,545 \\
Chiropractic practice & 1,703 \\
Skilled nursing facility & 2,643 \\
Medical practice & 3,552 \\
Home health agency & 602 \\
All others & 9,366 \\
\hline Total & $\mathbf{2 3 , 4 8 6}$ \\
\hline Sanction Type & Total Exclusions \\
\hline License revocation or suspension & 8,741 \\
Default on health education loan & 2,444 \\
Program-related conviction & 6,454 \\
Patient abuse or neglect & 2,877 \\
Conviction: controlled substance & 266 \\
All others & 2,699 \\
\hline Total & $\mathbf{2 3 , 4 8 6}$ \\
\hline Source: Orfice of Insector Gener &
\end{tabular}

Source: Office of Inspector General

concern physicians. Not surprisingly, evaluation and management coding, as well as documentation, makeup the most important facet of the 2002 work plan. Once again, the federal government is going to focus on the level of coding, office visits versus consultations and billing for residents' services.

In addition, the topic of human subject research protection

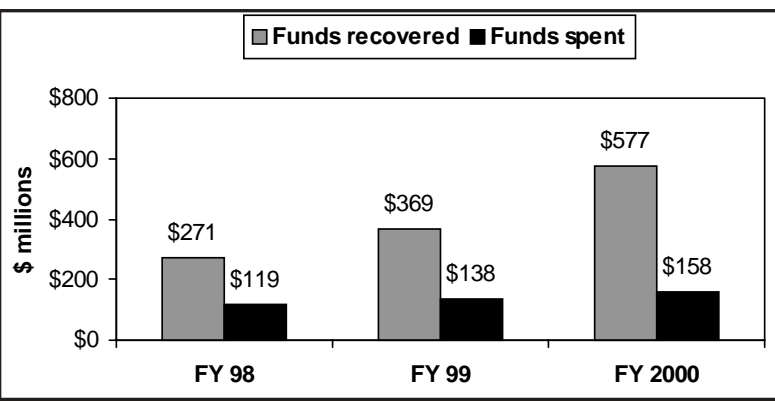

Fig 2. Health Care Fraud Enforcement: Funds returned to the Medicare Trust Funds vs. Funds appropriated from federal budget also is becoming an important subject for the OIG. Recent deaths in clinical trials have heightened the scrutiny in this area. The OIG believes that investigators have received reports that some physicians are coercing their patients into trials to meet recruitment protocols. In addition, it is also believed that, at some sites, physicians are rushing their way through the consent process; thus, physician abuse in clinical trials is an upcoming "hot" area. The OIG also believes that physicians are not well educated about and are also unfamiliar with their federal obligations regarding clinical trials, such as Food and Drug Administration (FDA) regulations in terms of good clinical practices, they may be unknowingly violating FDA guidelines in various arenas of clinical research. The OIG also is looking at Medicare payments to drug trial participants to see if physicians may be crossing the medical necessity criteria. However, most of the focus is at the present time on drug trials.

Another issue is advanced beneficiary notices. Evidence continues to mount on physician offices all over the country over the use of advanced beneficiary notices. Prac- 


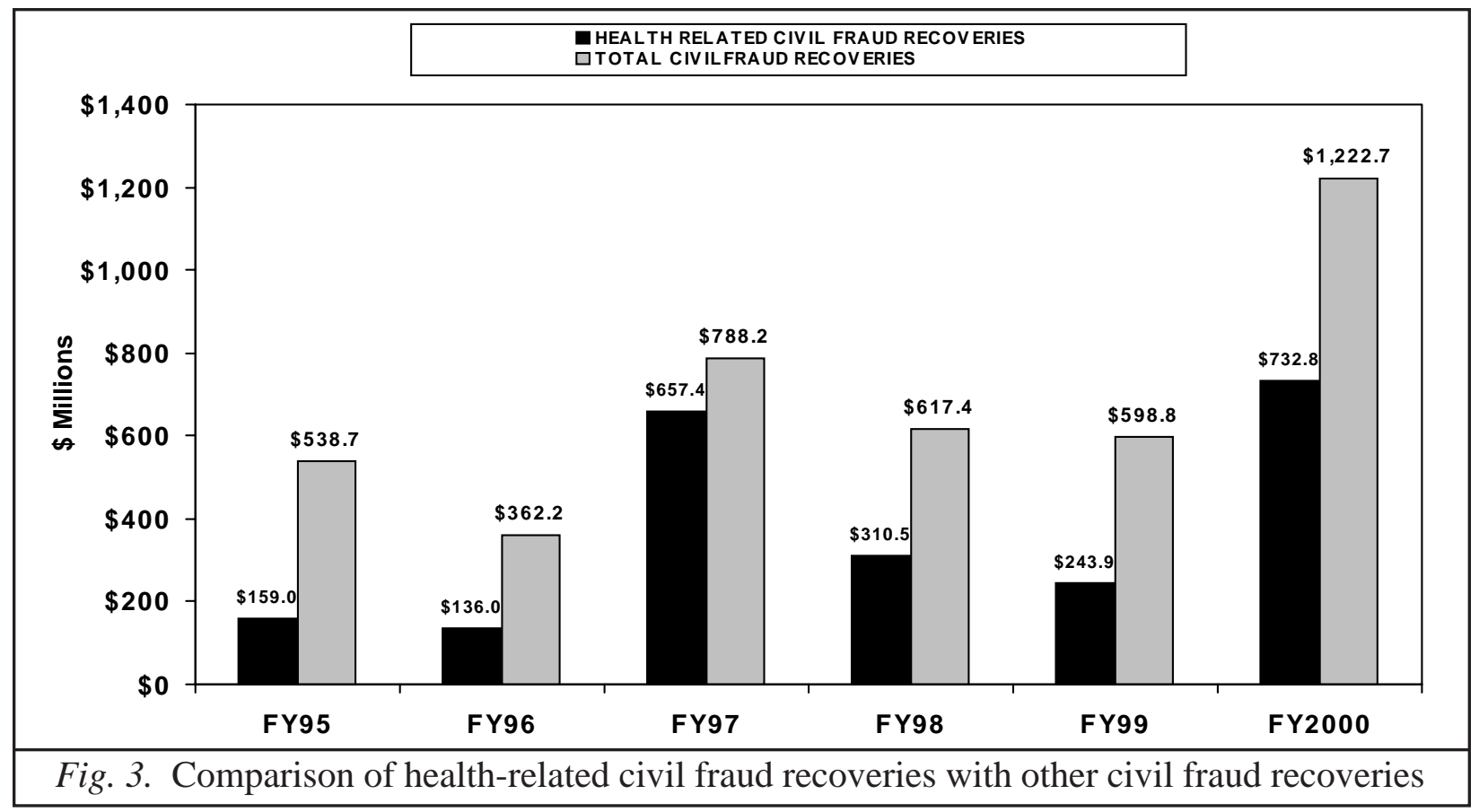

tices will be required to use a new advanced beneficiary notice form (CMS' R-131) beginning September 2002. The OIG will not only be paying more attention to this area, but will be tough and less forgiving of those practices that fail to use the forms correctly. Noncovered laboratory tests are the greatest source of confusion with advanced beneficiary notices. The CMS believes that it is the physician's responsibility to issue an advanced beneficiary notice even when physicians' offices only draw the specimens and ship them to the labs for processing. This is because many believe that the physician has the rapport with the patient; thus he/she should be getting the advanced beneficiary notices signed. Further, the OIG is also concerned about why physician practices are failing to estimate the cost of each service. In the opinion of CMS, grossly underestimated cost estimates are extremely problematic.

The OIG's oversight is also increasing on mental health cases, as these services are increasing. A percentage of the exclusions of mental health providers are also increasing. Considering that many interventional practices also provide mental health services, this is of a crucial issue. Thus, the OIG is expecting to release guidelines to help mental health professionals comply with federal regulations. However, these guidelines once again will not be mandatory. Statistics show that in 1999, Medicare allowed $\$ 185$ million in medically unnecessary mental health ser- vices. According to the OIG report, a year later, the program paid approximately $\$ 4.85$ billion for mental health services. While the OIG continues to scrutinize and heighten its oversight, the CMS believes that mental health services are extremely important for the community. According to its work plan, the OIG will assess the role of the substance abuse and mental health services administration in treating mental illness. In addition, Congress also may be working on bills that would mandate health plans to offer the same deductibles, copayments and scope of coverage for mental health services as offered for other healthcare services.

The OIG also calls for increased scrutiny of documents and documentation of medical necessity. As per the OIG, in fiscal year 2000, the CMS processed $\$ 11.9$ billion in claims that were incorrectly coded, not backed by documents or fraudulent. However, that is the lowest figure since the measurements began in 1996 and represents a $6.8 \%$ error rate. The total for 2000 is down $\$ 1.6$ billion from fiscal year 1999 , which was $\$ 13.5$ billion. It was also down from 1998 with an error rate of $\$ 12.6$ billion, 1997 with an error rate of $\$ 20.3$ billion and 1996 with an error rate of $\$ 23.2$ billion. In arriving at these calculations, the OIG looked at 5,234 Medicare claims from 610 beneficiaries and projected its findings nationally. The OIG attributed the waste primarily to physicians, skilled nursing and durable medical equipment manufacturers. Fur- 
ther, bad charges associated with inpatient hospitals were also significant. Finally, the OIG estimated that in fiscal year 2001, medically unnecessary services cost Medicare $\$ 5.23$ billion; incomplete or missing documentation cost the program $\$ 5.19$ billion; and coding errors cost at $\$ 2.06$ billion; totalling \$12.1 billion in errors (Fig. 4). The OIG also alluded to CPT codes 99232 and 99233 (subsequent hospital care); as well as 99214 (office or other outpatient visit for an established patient) as the most problematic areas. However, the most smallest error category was billing for noncovered services, accounting for $\$ 800$ million; which included prescription drugs, examinations to prescribe eyeglasses, and chiropractic services.

In 1997 , the OIG estimated that $50 \%$ of the rehab payments were improper. In a March 21, 2000, audit report, the OIG found that more than half the outpatient rehabilitation payments CMS made in the year ending June 30, 1998 , were not necessary, badly documented or not provided by licensed professionals. In response, the OIG and CMS are "turning up the heat" on outpatient rehabilitation facilities by various means. To arrive at this decision, the OIG reviewed 200 paid claims from outpatient rehabilitation facilities in Florida, Louisiana, Michigan, New Jersey, Pennsylvania, and Texas. Of the 200 claims, 108, or $54 \%$, contained unallowable or highly questionable services. Extrapolating the $54 \%$ error rate, the agency estimated that outpatient rehabilitation facilities in these six states improperly billed Medicare $\$ 173$ million during the review and Medicare overpaid outpatient rehabilitation facilities in these six states by $\$ 277$ million in calendar year 1997 out of a total national expenditure of $\$ 572$ million. The OIG identified three main reasons for the unnecessary payments:

- Records did not indicate patients' functional impairment;

- There was no evidence of a therapist actively participating in care of the patient; and

- Rehabilitation therapy was continued even after the patient had reached a plateau and no further progress was seen or expected.

Finally, one silver lining is that the CMS says not to worry about fee waivers. Physicians are concerned that unusual charitable practices could be considered illegal and would result in fraud police visiting their offices for waiving the copayments for poor patients. It appears that the OIG has changed its heart on this issue. The OIG, at least for now, does not plan any type of organized investigation into copay waiver practices. Providers are also permitted under Medicare Part B to waive copayments once they have made a good-faith effort to determine the financial condition of the beneficiary. The OIG has always been concerned about the routine waiver of copayments, which could be associated with serious violations of reimbursement rules.

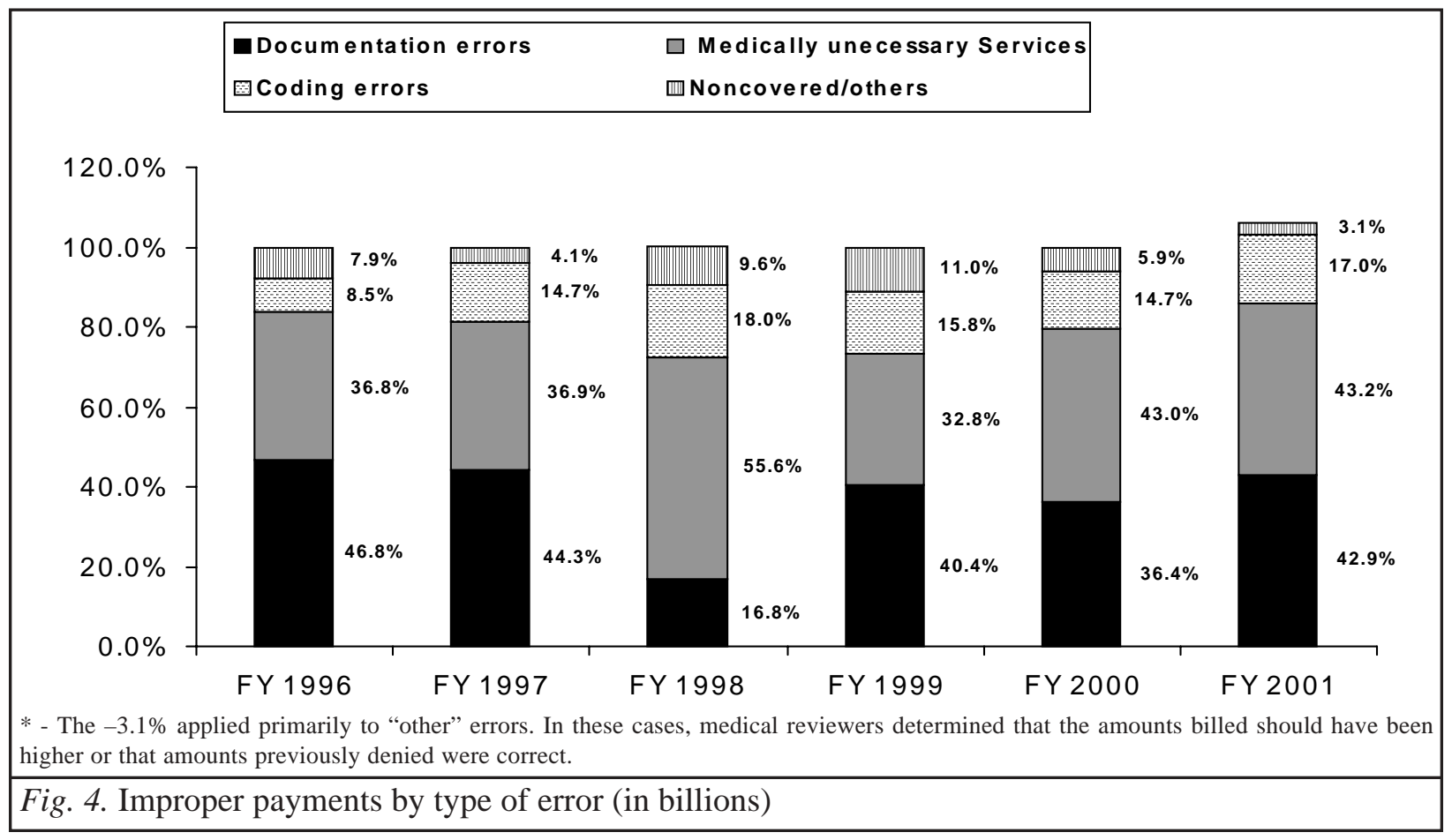


It is best to use an objective standard, preferably one set by one entity, to develop a workable definition of financial hardship to justify waiving a copay. Theoretically, one could use the Medicaid eligibility standards, food-stamp program standards, or federal poverty guidelines. However, financial hardship becomes extremely difficult to decide in temporary situations involving personal circumstances with a loss of job, divorce, or unfortunate catastrophic illness. In addition, waiving medical fees for services provided to other physicians, family, employees, and friends, is considered as courteous and has been a common practice among most practices. With evolving emphasis on fraud, or even the appearance of fraud, the appearance of inappropriateness has discouraged all such professional courtesies. The physicians should take into consideration that this practice is not automatically considered illegal as long as the decision is not based directly or indirectly on that person's ability to refer patients covered by federal healthcare programs to the practice, and it is not a consistent practice of waiving the entire fee for services to a group of people, including employees, physicians, or their family members. Thus, the important facts are that the recipient of the benefit should be in a position to directly or indirectly affect past or future referrals, and the act should not create a financial relationship that violates the self-referral restrictions. Finally, waiving the copayments for federal healthcare program patients who are not financially needy can put interventional pain practitioners in potential violation of the False Claims Act, because the government views the routine waiver of deductibles or copayments as a misrepresentation of the actual charge, which can be construed as a false claim.

\section{FRAUD AND ABUSE}

\section{Abuse}

Abuse is defined in many ways. However, the key words in the definition of abuse are knowingly or willfully. A provider's intent is the most significant factor in determining whether noncompliance is considered abuse, rather than a fraudulent practice (3). Abuse may, directly or indirectly, result in unnecessary costs to a program such as Medicare or Medicaid, improper payment, or payment for services that fail to meet professionally recognized standards of care or that are medically unnecessary. Abuse also involves payment for items or services for which there is no legal entitlement to payment. Fundamentally, in abuse, the physician or healthcare professional has not knowingly and willfully misrepresented facts to obtain payment.

The most common examples of abuse include, but are not limited, to:

- Performance of services, that are not "medically necessary,"

- Inappropriate medical record documentation,

- Inappropriate billing practices,

- Violations of Medicare limiting charge, and/or

- Violation of the participation agreement.

To summarize, abuse involves actions that are inconsistent with sound medical, business or fiscal practices.

\section{Fraud}

Fraud is much more serious than abuse and implies the intent to commit a crime. Fraud relates to intentional deception or misrepresentation to obtain some benefit, such as payment for medical services. Intent is an essential element in fraudulent billing.

Three types of fraud in healthcare services have been described. These include obvious fraud, incentives that promote overutilization, and matters of judgment or interpretation. Obvious fraud represents conduct that is indefensible and without controversy. Examples of obvious fraud include intentionally billing for services never provided, including "no shows;" misrepresenting the diagnosis to justify the services; applying for duplicate payment; and issuing certificates of medical necessity for patients unknown to the physician; and knowingly upcoding or unbundling (3).

The second category, the incentives that promote overutilization, is also troublesome under the antikickback statute, as well as Stark regulations. The third type of fraud involves matters of judgment or interpretation in which a large grey area of fraud can arise over the exercise of judgment. This involves selection of a level of service or the proper CPT code, unbundling and upcoding, etc. There is often a fine line between fraudulent conduct and legitimate disagreements over the interpretations of the clinical evidence. Inadvertent billing errors which occurred due to ignorance or misinterpretation of reimbursement policies also fall into this category. However, the Justice Department and the Centers for Medicare and Medicaid (CMS) maintain that there will be no prosecutions for billing errors. That only means 
that an occasional coding error is no reason for alarm and that the carrier will refer the matter to the OIG. However, practitioners should remember that repeated abuses can lead to fraud charges.

According to The Medicare Carrier's Manual for

Fraud Unit Procedures, Section 14011, Coordination with Carrier Medical Review unit's responsibilities includes looking for questionable billing patterns and practices. The term abuse describes incidents or practices of providers that are inconsistent with accepted sound medical practice. Abuse may, directly or indirectly, result in unnecessary costs to the program, improper payment, or payment for services that failed to meet professionally recognized standards of care, or that are medically unnecessary. Abuse involves payment for items or services when there is no legal entitlement to that payment and that provider has not knowingly and intentionally misrepresented facts to obtain payment.

If the medical review unit finds, or suspects, such practices, it should consult with the fraud unit to determine whether the case should be referred to the fraud unit for further action.

Medicare is most vulnerable to overutilization of medical and healthcare services. Abuse takes such forms as, but is not limited to, claims for services not medically necessary, or not medically necessary to the extent furnished.

Although these types of practices may be considered abusive, under certain circumstances, they may constitute or evolve into fraud. If a provider appears to have knowingly and intentionally furnished medically unnecessary services or filed claims for services not furnished as stated on the claim form, or made any false statement on the claim form to receive payment, the case is discussed with the fraud unit. If the fraud unit agrees that there is potential fraud, the Medical Review unit then refers the cases to the fraud unit. When reviewing such situations, do not assume that the abuse is the result of an error or misunderstanding of program requirements. At a minimum, ascertain whether there have been similar complaints or warnings, and whether the provider has been the subject of Medical Review previously.
The fraud unit often receives complaints alleging fraud that are determined to be abusive rather than fraudulent. When this occurs, the fraud unit will decide if it is more cost and time effective to complete the case or refer it to the Medical Review unit (4).

The message is that repetitive violations after notice(s) without any corrective action by the physician equates to fraud. Even though CMS is not interested in prosecuting billing errors, the local Medicare carrier can be instrumental in redefining such errors as fraud. Once that happens, the physician can be confronted with criminal, civil, and/or exclusionary sanctions. After this stage, the matter is no longer limited to negotiating an overpayment request with a carrier; but billing errors are translated to fraud and abuse.

\section{Fraud or Abuse?}

The distinction between fraud and abuse can be very important in determining the potential fines and penalties that might apply. In this regard, fraud is much more serious than abuse. However, the distinction between fraud and abuse is not crystal clear. There is a significant grey area. The degree of intent by the individual or entity under investigation is often the determining factor. It may start as a billing error identified by a local Medicare carrier as an abusive billing pattern but could turn into a full blown fraud case turned over to the OIG and/or the Department of Justice (DOJ) for criminal prosecution, specifically if added billing irregularities or any evidence of intent to defraud is discovered.

Fraud, as defined by CMS, is an intentional deception or misrepresentation that someone makes, knowing it is false, that could result in the payment of unauthorized benefits.

In contrast, abuse involves actions that are inconsistent with sound medical, business, or fiscal practices.

Thus, the primary difference between fraud and abuse is a person's intent. Abuse directly or indirectly results in higher costs to the healthcare program through improper payments (2). For fraud, persons should be aware that they were committing a crime. However, for an activity or scheme to be judged fraudulent, it does not have to be successful.

In defining persons who have filed a false claim, federal legislation specifies that this includes (4): 
.... any person who engages in a pattern or practice of presenting or causing to be presented a claim for an item or service that is based on a $\left(\mathrm{CPT}^{\mathrm{TM}}\right)$ code that the person knows or should know will result in a greater payment to the person than the code the person knows or should know is applicable to the item or service actually provided.

However, the problem with this statement is that there is always the danger that enforcement agencies could claim that there is sufficient evidence of fraudulent intent to pursue criminal sanctions.

The Health Insurance Portability and Accountability Act (HIPAA) also specifically includes the following language with regards to fraud (4): “ . . . the term should know means that a person .. (A) acts in deliberate ignorance of the truth or falsity of the information; or (B) acts in reckless disregard of the truth or falsity of the information, and no proof of specific intent to defraud is required."

\section{PREVALENCE OF FRAUD AND ABUSE}

No one questions the need to identify and prosecute individuals involved in fraudulent activities. However, it is believed that the vast majority of physicians are honest and make attempts to comply with the very complex laws and regulations of modern healthcare, in addition to attending to patients' medical needs. Thus, honest mistakes by physicians are no more indicative of fraudulent billing than a healthcare carrier's failure to issue a correct payment in response to a clean health insurance claim form is indicative of fraud, either on the part of the government or private insurer. It has been estimated that the annual incidence of healthcare fraud is approximately $10 \%$, which translates to over $\$ 100$ billion annually in the United States (5). However, this has been questioned by many authorities. This is another instance of random estimations. The implication of $\$ 100$ billion or $\$ 100,000$ million fraud is serious. If physician services constitute $30 \%$ of the entire healthcare expenditures, physician fraud will be $\$ 30,000$ million (4) with 750,000 doctors in the United States, and 450,000 of them in office based practice each doctor would be committing $\$ 40,000$ or $\$ 70,000$ fraud, unless most of the fraud is coming from hospitals and major corporations. If the entire fraud is attributed to physician payments each physician of 750,000 is responsible for $\$ 133,333$ or each physician of 450,000 is responsible for $\$ 122,222$, of fraudulent activity. Further, these estimations are based on a trillion dollar healthcare costs. The healthcare costs (pro- jected) for 2001 were $\$ 1,423.8$ billion, which will translate $10 \%$ fraud into $\$ 142.38$ billion or $\$ 142,380$ million provided there has not been significant increase in fraudulent activity or even abuse. Statistically speaking, this will further increase the amounts attributed to each provider, as growth of physicians has been slower than growth of healthcare costs.

While the federal government has become far more aggressive in identifying and prosecuting healthcare professionals and entities for fraud and abuse, private insurance also are becoming not only more active but are also pursuing fraud and abuse. Recent Federal Bureau of Investigation statistics show that $75 \%$ of investigations are related to government agencies, either Medicare or Medicaid; whereas $25 \%$ of the cases are investigated secondary to the complaints of private insurers.

\section{IMPLICATIONS}

Implications are much less serious if the issues are handled at local carrier level; however, once the issue is referred to law enforcement agencies, it becomes serious.

Identification of improper billing practices by a Medicare carrier requires the physician to repay any monies received inappropriately, along with interest. This is based on the carrier's discretion, which may include a return of funds for a relatively small number of services or calculation of the overpayment percentage from a small sample of patient encounters to determine the amounts to be recouped for payments received over several years for similar services.

For example, simplifying the sampling process, assume a Medicare carrier audited documentation of 20 patient encounters and determined that a physician upcoded seven claims, which resulted in an overpayment of \$175 or \$25 per claim. If a physician is lucky, the carrier may simply ask for repayment of $\$ 175$ plus interest for the above encounters reviewed. In addition, the carrier may also offer education with regards to proper billing practices. However, more commonly than uncommonly with increasing frequency, Medicare carriers are asking for repayment of $\$ 25$ each on $28.5 \%$ of similar services provided by the physician billed to that carrier over the past 5 years, which could result in a repayment request of hundreds of thousands of dollars.

That is the good news. The bad news is that carriers can also refer the case to the OIG or DOJ for further investiga- 
tions, and that they are doing it frequently. Once it is referred to law-enforcement agencies, the government may pursue criminal prosecution, civil monetary penalties or exclusion from participation in the federal health programs. Where fraudulent intent is established, exclusion will not stop there, but could then lead to loss of hospital and other facility privileges and denial of participation in managed care plans.

\section{FRAUD AND ABUSE STATUTES}

Fraud and abuse statutes not only include various federal laws but also state laws, as well as antikickback statutes and Stark regulations. A number of federal statutes may be used as the basis for healthcare fraud prosecution. In addition, many states also have independently enacted legislation aimed at healthcare fraud and abuse. The most commonly used statutes for prosecuting or facilitating such a prosecution of healthcare fraud or abuse include (6):

- HIPAA of 1996,

- The False Claims Act,

- Health Care Fraud,

- Theft or embezzlement,

- Obstruction of criminal investigations of healthcare offenders,

- The False Statement Statute,

- Mail and wire fraud statutes,

- The Social Security Act,

- Civil monetary penalties,

- Criminal penalties, and/or

- Stark laws.

In addition, federal legislation such as the Racketeer Influenced and Corrupt Organization Act may be used to prosecute healthcare fraud. Antikickback statutes and Stark regulations are quite frequently used to facilitate prosecution of fraud and abuse.

\section{Health Insurance Portability and Accountability Act of 1996}

The HIPAA is the most significant legislative initiative with substantial implications for the to healthcare industry on issues of fraud and abuse. The HIPAA added substantial funding for fraud and abuse activities for several agencies, which included the CMS, FBI and OIG. The act not only provides the funding and also lets the agencies utilize recoveries from successfully prosecuted cases but also provides incentives to the various enforcement agencies to identify and prosecute fraud cases.

The HIPAA expanded the powers of the government with respect to healthcare fraud and abuse. It appears that, based on this act, the OIG can exclude from Medicare or Medicaid responsible owners, officers, and managing employees of companies that have committed fraud or have been excluded from Medicare, even if the investor, officer, or employee had no knowledge of the wrongdoing. Further, the DOJ can subpoena or seize the records in any healthcare fraud investigation regardless of whether the investigation involves a federal agency such as Medicare or Medicaid. The HIPAA also expands fraud and abuse actions to certain offenses against nongovernmental payors. Further, it increases penalties for fraud and abuse and offers incentives payable to informants and government departments participating in fraud cases.

In summary, the HIPAA creates a new category of offense, known as federal healthcare offense, which includes;

- Healthcare fraud,

- Making false statements,

- Theft and embezzlement,

- Obstruction of criminal investigations,

- Money laundering.

However, under HIPAA, unfortunately, these categories of crimes not only apply to all governmental agencies, but also to private payors.

\section{Provisions}

Provisions of HIPAA include the following:

- Civil monetary penalties of $\$ 10,000$ per infraction plus three times the amount of the overpayment;

- Consideration of an infraction as a line item on a claim form, resulting in a $\$ 10,000$ or more penalty every time a fraudulent claim is filed;

- Imposition of \$10,000 per day fines for organizations that continue any "investor" relationship or continue employing a person who has been excluded from any federal healthcare program;

- Mandatory exclusion from Medicare for 5 to 10 years for certain offenses;

- Application of Medicare and Medicaid exclusion penalties to all other federal healthcare programs, including Civilian Health and Medical Program of the Uniformed Services, Veteran's Affairs, 
Blackland, and Federal Employee Health Benefits Program.

- Consideration of "Deliberate ignorance" or "reckless disregard of the truth" as the test to whether an individual should have known that an activity was fraudulent;

- Specific definition of upcoding of evaluation and management services;

- Penalties for offering inducements to Medicare beneficiaries or Medicaid recipients;

- Penalty of $\$ 5,000$ or three times the cost of services for any physician who certifies unneeded home healthcare;

- Forfeiture and confiscation of any assets, including personal property, acquired directly or indirectly from funds related to fraudulent activity;

- A $\$ 25,000$ penalty per infraction for health maintenance organizations (HMOs) that fail to comply with Medicare contracts or federal regulations.

\section{Federal False Claims Act}

The Federal False Claims Act (31 USC §3729) permits not only the government, but also citizens civil action against physicians and other providers filing fraudulent claims. The False Claims Act provides for a civil penalty of $\$ 5,000$ to $\$ 10,000$ per false claim, plus three times the amount of damage that the government sustains (4).

This act is often used when a physician bills for services which were not actually rendered.

According to the law, any person is subject to penalty who commits one of the following actions:

1. Knowingly presents, or causes to be presented, to an officer or employee of the US government or a member of the armed forces . . a false or fraudulent claim for payment or approval (the term knowingly includes "acting in reckless disregard ..." or in "deliberate ignorance of the truth or falsity of information");

2. Knowingly makes, uses, or causes to be made or used, a false record or statement to get a false or fraudulent claim paid or approved by the government;

3. Conspires to defraud the government by getting a false or fraudulent claim allowed or paid;

4. Has possession, custody, or control of property or money used, or to be used, by the government and, intending to defraud the government or willfully to conceal the property, delivers, or causes to be delivered, less property than the amount for which the person receives a certificate or receipt;

5. Is authorized to make or deliver a document certifying receipt of property used, or to be used, by the government and, intending to defraud the government, makes or delivers the receipt without completely knowing that the information on the receipt is true;

6. Knowingly buys, or receives as a pledge of an obligation or debt, public property from an officer or employee of the government, or a member of the armed forces, who lawfully may not sell or pledge the property; or

7. Knowingly makes, uses, or causes to be used, a false record or statement to conceal, avoid, or decrease an obligation to pay or transmit money or property to the government; such an individual is liable to the US government for a civil penalty of not less than $\$ 5,000$ and not more than $\$ 10,000$, plus three times the amount of damages which the government sustains because of the acts. Note that the $\$ 5,000$ to $\$ 10,000$ penalty is per false claim.

The bad news is that the act also states: "the United States shall be required to prove all the essential elements of the cause of action, including damages, by a preponderance of the evidence." Thus, the government does not have to prove its false claims allegations beyond a reasonable doubt.

Private citizens often bring suit on behalf of themselves and the government against fraudulent healthcare providers by alleging violation of the False Claims Act. These types of suits are called qui tam suits, also known as "whistleblower" suits, with persons receiving $10 \%$ to $30 \%$ of the total recovery plus reasonable attorney fees. The only recourse for the physician or another provider is that if the qui tam plaintiff is the employee and if it were demonstrated that the employee intentionally filed an action knowing that the allegations were not true, this plaintiff might be responsible for legal fees to the extent that the government does not participate in the case and where the action is not successful. Qui tam suits generally are very expensive and long-lasting.

The OIG promulgated the provider self-disclosure protocol in 1999, which provides detailed guidance to healthcare providers that decide voluntarily to disclose irregularities in their dealings with federal healthcare programs. However, the protocol does not include any assurance that would prevent a qui tam plaintiff's filing an action, even 
after repayment has been made subject to the selfdisclosure guidelines.

The statute of limitations under the False Claims Act runs for 6 years after the commission of an offense. However, this period may be extended to approximately 10 years when certain facts do not come to light within the normal 6-year period.

\section{Health Care Fraud}

Description of unlawful conduct: It is a crime to knowingly and willfully execute (or attempt to execute) a scheme to defraud any health care benefit program, or to obtain money or property from a health care benefit program through false representations. Note that this law applies not only to Federal health care programs as well.

Penalty for unlawful conduct: The penalty may include the imposition of fines, imprisonment of up to 10 years, or both. If the violation results in serious bodily injury, the prison term may be increased to a maximum of 20 years. If the violation results in death, the prison term may be expanded to include any number of years, or life imprisonment.

Description of unlawful conduct: It is a crime to knowingly and willfully embezzle, steal or intentionally misapply any of the assets of a health care benefit program. Note that this law applies not only to Federal health care programs, but to most other types of health care benefit programs as well.

Penalty for unlawful conduct: The penalty may include the imposition of a fine, imprisonment of up to 10 years, or both. If the value of the asset is $\$ 100$ or less, the penalty is a fine, imprisonment of up to a year, or both.

Description of unlawful conduct: It is a crime to knowingly and willfully falsify or conceal a material fact, or make any materially false statement or use any materially false writing or document in connection with the delivery of or payment for health care benefits, items or services. Note that this law applies not only to Federal health care programs, but to most other types of health care benefit programs as well.

Penalty for unlawful conduct: The penalty may include the imposition of a fine, imprisonment of up to 5 years, or both.
Description of unlawful conduct: It is a crime to willfully prevent, obstruct, mislead, delay or attempt to prevent, obstruct, mislead, or delay the communication of records relating to a Federal health care offense to a criminal investigator. Note that this law applies not only to Federal health care programs, but to most other types of health care benefit programs as well.

Penalty for unlawful conduct: The penalty may include the imposition of a fine, imprisonment of up to 5 years, or both.

\section{False Statements}

The penalty for making false statements is imprisonment up to 5 years and fines up to $\$ 250,000$ for individuals, and possibly more if the amount of gain is large.

However, once again, unfortunately, HIPAA extended Section 1001 of the False Claims Act, which is similar to 287 , to private healthcare plans in addition to government programs.

This section is commonly used to prosecute physicians for billing services not rendered, and hospitals for knowingly including improper expenditures on their cost reports, and, finally, for billing services not personally performed.

\section{Mail and Wire Fraud}

Mail and wire fraud statutes allow for imprisonment for up to 5 years, and fines of not more than $\$ 1,000$ per occurrence for a fraudulent scheme in which claims or statements are sent by mail, telephone, radio waves, etc. Many providers believe that private carriers such as Fed Express do not fall under this law. However, transmittal of almost any fraudulent claim might violate mail or wire fraud provisions, which includes using private or commercial interstate carriers.

Once again, HIPAA extended section 1341 and 1343 to private healthcare programs in addition to government programs.

\section{Social Security Act Civil Monetary Penalties}

The government may impose civil monetary penalties of up to $\$ 10,000$ per claim if the physician knew or should have known the claim was false. In addition, a civil monetary action may be brought after successful criminal 
prosecution. The Medicare Carrier's Manual illustrates that penalties may be imposed where the secretary determines that a person presents or causes to be presented a claim for:

- An item or service not provided as claimed;

- An item or service that is false or fraudulent;

- A physician's service provided by a person who was not a licensed physician, whose license had been obtained through misrepresentation, or who improperly represented he/she was a certified specialist; or

- An item or service furnished by an excluded person.

The secretary may also impose a civil monetary penalty against a person who presents or causes to be presented a request for payment in violation of:

- A Medicare assignment agreement;

- An agreement with a state Medicaid agency not to charge a person in excess of permitted limits;

- A Medicare participating physician/supplier agreement; or

- An agreement not to charge patients for services denied as a result of a determination of an abuse of the prospective payment system (PPS). A person that gives false or misleading information regarding PPS that could reasonably be expected to influence a discharge decision is also subject to imposition of a civil monetary penalty.

Other situations where civil monetary penalties may be applied include:

- Violation of assignment requirements for certain diagnostic clinical lab tests;

- Violation of assignment requirements for nurse anesthetist services;

- Any supplier who refuses to supply rented durable medical equipment supplies without charge after rental payments may no longer be made (effective January 1, 1989);

- Nonparticipating physician or supplier violation of charge limitation provisions for radiology services (effective January 1, 1989);

- Violation of assignment requirement for physician assistant services;

- Medicare nonparticipating physician's violation of limiting charge limits;

- Nonparticipating physician's violation of charge limitations;
- Physician billing for assistants at cataract surgery without prior approval of Peer Review Organization;

- Nonparticipating physician's violation of refund requirements for medically unnecessary services;

- Nonparticipating physician's violation of refund provision for unassigned claims for elective surgery (where an elective surgical form was not provided);

- Physician charges in violation of assignment provision for certain purchased diagnostic procedures where markup is prohibited or where a payment is prohibited for these procedures due to failure to disclose required information;

- Hospital unbundling of outpatient surgery costs; and

- Hospital and responsible physician "dumping" of patients.

\section{Antikickback Statute}

The antikickback statute has prohibited payments for referrals since the 1970 s. The antikickback statute prohibits:

1. The knowing and willful offer or making of payment (including a kickback, bribe or rebate) to induce a referral of a Medicare or Medicaid patient;

2. Solicitation or receipt of such payments;

3. Knowingly and willfully inducing, making, or causing to be made any false statement or material misrepresentation in an application for Medicare or Medicaid payment; and

4. Any payment to a physician as an inducement to limit or reduce necessary medical services to Medicare or Medicaid beneficiaries.

Violation of this statute is a felony. The violator is not only subject to civil penalties but also subject to criminal penalties, along with exclusion from Medicare, Medicaid and other federal healthcare programs.

\section{Original Safe Harbors}

Congress created safe harbors to describe activities in which one can safely engage without violating antikickback laws. The first 13 safe harbors were originally promulgated in 1991 and 1992. Subsequently, in 1999, some of the original ones were clarified or modified slightly. The list of safe harbors is as follows (4):

1. Investment interests in large publicly held healthcare companies,

2. Investments in small health care joint ventures, 
3. Space rental,

4. Equipment rental,

5. Personal services and management contract,

6. Sales of retiring physicians' practices to other physicians,

7. Patient referral services (such as those maintained by a hospital),

8. Discounts,

9. Warranties,

10. Employee compensation,

11. Group purchasing,

12. Hospitals waiving coinsurance and deductibles for indigents, and

13. Inducements offered to potential enrollees by HMOs and similar discounts offered to HMOs, etc., by participating providers.

\section{New Safe Harbors}

New safe harbors include the following:

1. Investments in ambulatory surgical centers,

2. Joint ventures in underserved areas,

3. Practitioner recruitment in underserved areas,

4. Sales of physician practices to hospitals in underserved areas,

5. Subsidies for obstetric malpractice insurance in underserved areas,

6. Investments in group practices,

7. Specialty referral arrangements between providers, and

8. Cooperative hospital services organizations.

\section{Stark Regulations}

Limits on self referral were first enacted into a law known as the Stark Amendment as part of the Omnibus Budget Reconciliation Act of 1989. Referrals of Medicare or Medicaid beneficiaries for multiple designated services are prohibited under Stark II, if the physician has a financial relationship (not just ownership) with the entity providing the services. Some of these categories are extremely broad, which include the following but one not limited to (4):

1. Clinical laboratory services;

2. Physical therapy services;

3. Occupational therapy services;

4. Radiology or other diagnostic services;

5. Radiation therapy services and supplies;

6. Durable medical equipment and supplies;
7. Parenteral and enteral nutrients, equipment, and supplies;

8. Prosthetics, orthotics and prosthetic devices and supplies;

9. Home health services;

10. Outpatient prescription drugs; and

11. Inpatient and outpatient hospital services.

Often physicians are confused about the antikickback statute and Stark legislation. The following are the differences (4):

- The Stark Law is a civil statute that generally prohibits physicians from making referrals for clinical laboratory or other designated health services to entities in which the physicians have ownership or other financial interests and prohibits entities from presenting or causing to be presented claims or bills to any individual, third-party payor, or other entity for designated health services furnished pursuant to a prohibited referral.

- The antikickback statute, on the other hand, is a criminal statute that prohibits the knowing and willful offer, payment, solicitation, or receipt of remuneration to induce federal health care program business.

- Both laws are directed at the problem of inappropriate financial incentives' influencing medical decisionmaking. This similarity notwithstanding, the statutes are different in scope and structural approach. Under the Stark Law, physicians may not refer patients for certain designated health services to entities from which the physicians receive financial benefits, except as allowed in enumerated exceptions. A transaction must fall entirely within an exception to be lawful under the Stark Law.

- The antikickback statute, on the other hand, establishes an intent-based criminal prohibition with optional statutory and regulatory safe harbors that do not purport to define the full range of lawful activity. Rather, safe harbors provide a means of assuring that payment practices are not illegal. Payment practices that do not fully comply with a safe harbor may still be lawful if no purpose of the payment practice is to induce referrals of federal health care program business.

General exceptions to both ownership and compensation arrangements have been identified. These include physician services, in-office ancillary services, prepaid plans, and other permissible exceptions. 


\section{DESCRIPTION OF UNLAWFUL CONDUCT}

\section{False Statements and Representations}

It is a crime to knowingly and willfully:

- make, or cause to be made, false statements or representations in applying for benefits or payments under all Federal health care programs;

- make, or cause to be made, any false statement or representation for use in determining rights to such benefit or payment;

- conceal any event affecting an individual's initial or continued right to receive a benefit or payment with the intent to fraudulently receive the benefit or payment either in an amount or quantity greater than that which is due or authorized;

- convert a benefit or a payment to a use other than for the use and benefit of the person for whom it was intended;

- present, or cause to be presented, a claim for a physician's service when the service was not furnished by a licensed physician;

- for a fee, counsel an individual to dispose of assets in order to become eligible for medical assistance under a State health program, if disposing of the assets results in the imposition of an ineligibility period for the individual.

\section{Anti-Kickback Statute}

It is a crime to knowingly and willfully solicit, receive, offer or pay remuneration of any kind (eg, money, goods, services):

- for the referral of an individual to another for the purpose of supplying items or services that are covered by a Federal health care program; or

- for purchasing, leasing, ordering or arranging for any good, facility, service or item that is covered by a Federal health care program.

There are a number of limited exceptions to the law, also known as "safe harbors," which provide immunity from criminal prosecution and which are described in greater detail in the statue and related regulations (found at 42 CFR 1001.952 and at www.hhs.gov/oig/ak/ index.htm\#OIG Safe Harbor Regulations). Current safe harbors include:

- investment interests;
- space rental;

- equipment rental;

- personal services and management contracts;

- sale of practice;

- referral services;

- warranties;

- discounts;

- employment relationships;

- waiver of Part A co-insurance and deductible amounts;

- group purchasing organizations;

- increased coverage or reduced cost sharing under a risk-basis or prepaid plan; and

- charge reduction agreements with health plans.

\section{PENALTY FOR UNLAWFUL CONDUCT}

The penalty may include the imposition of a fine of up to $\$ 25,000$, imprisonment of up to 5 years, or both. In addition, the provider can be excluded from participation in Federal health care programs. The regulations defining the aggravating and mitigating circumstances that must be reviewed $b$ the OIG in making an exclusion determination are set forth in 42 CFR Part 1001.

\section{CRIMES BY HEALTHCARE PROVIDERS}

The twenty-first century has been a banner performance for governmental agencies with recoveries from a single healthcare provider amounting to a record 745 million in criminal and civil penalties from the Columbia-HCA Healthcare Corporation. The FBI has described healthcare frauds as its highest priority white-collar crimes (9). Approximately 500 FBI agents work almost exclusively on healthcare frauds in close cooperation with the Inspector General of the Department of Health and Human Services, state's attorney general, and district attorneys throughout the United States. As a result, hundreds of physicians, nurses, hospital administrators, accountants, and even billing clerks have received long-term prison sentences. The FBI claims that the fraudulent providers of medial care are frequently of the most incompetent physicians, nurses and home care operators. The US Department of Justice issued prosecution criteria for healthcare frauds that are especially applicable to corporations. Some of the criteria are listed in Table 5. The directive points out that even minimal wrongdoing may justify criminal prosecution of the misbehavior was persuasive, was carried out by employees, and was known by the company's top managers. Conversely, the document 
Table 5. Prosecution criteria for crimes by healthcare providers

The nature and seriousness of the wrongdoing

The persuasiveness of the misconduct

History of similar wrongdoing by the individual or the organization

Voluntary disclosure

Willingness to cooperate in the investigation

The absence or inadequacy of corporate complaints

programs

The corrective actions taken

The consequences of the lawbreaking

The sufficiency of non-criminal sanctions

Adapted and modified from Twardy (9)

also states that single acts by a rogue employee may not be sufficient justification for criminally charging the employer. Thus, numerous physicians are regularly being convicted for submitting improper claims and shortchanging patients on medical examinations and treatment (9). Apparently the FBI receives hundreds of tips from patients who suspect, or have detected, possible fraud by their healthcare providers.

The ongoing, unprecedented scrutiny, aided by a high level of computerization and widespread use of undercover agents, has brought to light a variety of crimes committed by physicians, nurses, pharmacists, hospitals, clinics, nursing homes and other healthcare practitioners and facilities (9). Twardy (9) stated, "even though small in number, these pill pushers, squawks, and well fed cheats can give the medical profession a 'black eye.' Their creativity in stealing appears to be unlimited in both scope and ingenuity."

The National Association of Attorneys General (NAAG), based on the overview of some of the schemes in the 1999 and prior reports, listed various examples of fraud as illustrated in Table 6.

Overutilization includes using treatments, including office visits, laboratory tests, therapy, and prescriptions, that are not required. Pharmacy fraud involves billing for prescriptions and supplies not delivered or providing lower priced or generic products and billing for higher priced medications or supplies. Billing fraud is the most important aspect involving physicians. This involves billing for services not needed or not performed, billing for non-existent patients, or billing for products not needed or not supplied. Unbundling, upcoding, and kickbacks
Table 6. Examples of fraud in healthcare

Overutilization
Pharmacy fraud
Billing fraud
Marketing and enrollment frauds
Frauds in the procure of Medicaid contracts
Durable equipment or supplies fraud
Supplies fraud
Unbundling
Upcoding
Legal scams
Kickbacks
Adapted and modified from Twardy (9)

are some of the other important aspects of healthcare fraud and abuse by physicians.

\section{CONCLUSION}

Fraud and abuse is not only an important issue for the federal government but also for medical practices in general and interventional pain management practices in particular. It is crucial to understand that the federal government has enacted over the years a comprehensive strategy to fight healthcare waste, fraud and abuse. Its efforts have been paid off as the OIG announced that improper Medicare payments to doctors, hospitals and other healthcare providers declined $54 \%$ from fiscal year 1996 to fiscal year 2001. Under HIPPA's healthcare fraud and abuse control program, HHS reported more than $\$ 1.9$ billion in fines and restitution returned to Medicare trust fund during fiscal years 1997, 1998 and 1999. In addition, HHS also excluded more than 23,186 individuals and entities from doing business with Medicare, Medicaid and other federal and state healthcare programs for engaging in fraud or other professional misconduct. Even though in a statement before the House Budge Committee, OIG reported that they are not interested in providers who make innocent billing errors, but rather they are interested in providers who intentionally set out to defraud the Medicare program or abuse Medicare beneficiaries. However, the distinction between fraud and abuse is not only crystal clear but a mistake may start as a billing error identified by a local Medicare carrier as an abused billing pattern which could turn into a full blown fraud case turned over to the OIG and/or DOJ for criminal prosecution, specifically if added billing irregularities are any evidence of intent to defraud is discovered. The prevalence of fraud and abuse has been estimated to $10 \%$ of national healthcare costs, which was shown to be $\$ 142.38$ trillion in 2001 , 
which translates to $\$ 142,380$ millions. Thus, it is essential for interventional pain physicians to understand multiple implications of fraud and abuse and be compliant with all types of regulations.

\section{REFERENCES}

1. Statement for the record to the house budget committee healthcare task force: Medicare program: Reducing improper payments and Fraud, Office of Inspector General, Department of Health and Human Services:July, 2000.

2. OIG report 2002.

3. Health Care Fraud and Abuse. A Physician's Guide to Compliance, AMA Press, Chicago, 2001.
4. Health care fraud and abuse. In Health Care Fraud and Abuse. A Physician's Guide to Compliance, AMA Press, Chicago, 2001, pp 1-26.

5. Orient JM. Can "Health care fraud" be ended? Medical Sentinel, July/Aug 1998, pp. 124-130.

6. HCFA Program Memorandum AB-00-72.

7. Fraud and abuse statutes. In Health Care Fraud and Abuse. A Physician's Guide to Compliance, AMA Press, Chicago, 2001 pp 49-78.

8. Entities involved in fraud and abuse investigations. In Health Care Fraud and Abuse. A Physician's Guide to Compliance, AMA Press, Chicago, 2001 pp 121-130.

9. Twardy S. Crimes by Health Care Providers. In Sanbar S, Gibofsky A, Firestone MH et al (eds). Legal Medicine. Fifth Edition. Mosby, St. Louis 2001; pp 163-185. 